\title{
Clinical Presentation of Gastroesophageal Reflux Disease: A Prospective Study on Symptom Diversity and Modification of Questionnaire Application
}

\author{
Ryan Broderick ${ }^{a}$ Karl-Hermann Fuchs ${ }^{a}$ Wolfram Breithaupt ${ }^{b}$ Gabor Varga ${ }^{b}$ \\ Thomas Schulz $^{b}$ Benjamin Babic ${ }^{c}$ Arielle Lee ${ }^{a}$ Frauke Musial ${ }^{d}$ Santiago Horgan ${ }^{a}$ \\ ${ }^{a}$ Department of Surgery, Center for the Future of Surgery, University of California San Diego, La Jolla, CA, USA; \\ ${ }^{b}$ Department of General- and Viszeral-Surgery, AGAPLESION Markus Krankenhaus, Frankfurt, Germany; ${ }^{C}$ Department of \\ Surgery, University of Mainz, Mainz, Germany; ${ }^{d}$ NAFKAM Department of Community Medicine Unit, The Artic University of \\ Norway, Tromso, Norway
}

\section{Keywords \\ Gastroesophageal reflux disease · Gastroesophageal reflux disease-symptoms - Heartburn - Regurgitation . Gastroesophageal reflux disease-diagnosis}

\begin{abstract}
Introduction: Symptoms occurring in gastroesophageal reflux disease (GERD) such as heartburn, regurgitation, thoracic pain, epigastric pain, respiratory symptoms, and others can show a broad overlap with symptoms from other foregut disorders. The goal of this study is the accurate assessment of symptom presentation in GERD. Methods: Patients with foregut symptoms were investigated for symptoms as well as endoscopy and gastrointestinal-functional studies for presence of GERD and symptom evaluation by standardized questionnaire. Questionnaire included a graded evaluation of foregut symptoms documenting severity and frequency of each symptom. The three types of questionnaires include study nurse solicitated, self-reported, and free-form self-reported by the patient. Results: For this analysis, 1,031 GERD patients (572 males and 459 females) were enrolled. Heartburn was the most frequently reported chief complaint, seen in $61 \%$ of patients. Heartburn and regurgitation are the most
\end{abstract}

(c) 2019 S. Karger AG, Basel

\section{karger@karger.com}

www.karger.com/ddi common (82.4/58.8\%, respectively) in overall symptom prevalence. With regard to modification in questionnaire technique, if patients fill in responses without prompting, there is a trend toward more frequent documentation of respiratory symptoms (up to $54.5 \%[p<0.01]$ ), fullness (up to $93.9 \%)$, and gas-related symptoms ( $p<0.001)$. Self-reported symptoms are more diverse (e.g., throat-burning [12\%], mouth-burning [9\%], globus [6\%], dyspnea [9\%], and fatigue [7\%]). Conclusions: GERD symptoms are commonly heartburn and regurgitation, but overall symptom profile for patients may change depending on the type of questionnaire.

๑) 2019 S. Karger AG, Basel

\section{Introduction}

Since gastroesophageal reflux disease (GERD) has a prevalence of $20 \%$ in industrialized countries, symptoms associated with the disease are common in these populations $[1,2]$. In order to define GERD, the authors of the Montreal classification relied heavily on symptoms and their effect on patients: "GERD is a condition which develops when the reflux of stomach contents causes troublesome symptoms and/or complications" [1]. These 
symptoms can reduce patient's well-being and have a negative influence on the quality of life $[3,4]$.

In many studies, GERD symptoms are used to define the study populations [5-13]. Other studies, however, have some evidence that symptoms are not always reliable as a guide to the diagnosis of GERD [14-17]. GERD symptoms such as heartburn, regurgitation, thoracic pain, epigastric pain, respiratory symptoms, globus, and others show a broad overlap with symptoms from other esophageal and gastric disorders such as dyspepsia, esophageal motility disorders, functional heartburn, hypersensitive esophagus, irritable stomach and bowel, and somatoform disorders [1, 14-17]. The wide array of symptoms and potential diagnoses make one consider if there is a specific questioning technique or symptom profile that is more highly suggestive of GERD. Klauser et al. [18] have stated that heartburn and regurgitation are the most typical symptoms characterizing GERD, but in clinical practice, a large variety of esophageal and extra-esophageal symptoms can be reported.

Over the last 3 decades, our team had documented symptoms of GERD patients in a large data bank. Initially, the evaluations were standardized and leaned heavily on the early DeMeester symptom score and Gastrointestinal Quality of Life Index [19-22]. Several years later, these questions were validated within the project of creating a symptom questionnaire featuring 53 items to determine somatoform tendencies [17]. With the exception of respiratory symptoms, all items in this current questionnaire differentiated significantly between healthy volunteers and patients with foregut symptoms [17].

The goals of this study are to determine the diversity and most common symptoms of GERD in large patient populations over time. Additionally, we aim to determine if the method of questioning is significant in altering the symptom profile of GERD patients.

\section{Methods}

\section{Study Design}

Over the course of more than 2 decades, our working group had the opportunity to investigate a large population of patients with GERD in a specialized center for benign esophageal and gastric disorders. All patients with foregut symptoms referred for further exploration of esophageal and/or gastric disease underwent a history and physical examination. The symptoms of the patients were evaluated by a standardized questionnaire over the complete time period from 1995 to 2017. Only the method of application for the questionnaires was changed over time, as described in detail below. All patients received an upper gastrointestinal endoscopy and esophageal manometry. In more recent years, a high-resolution manometry was performed [23]. The presence of pathologic reflux was evaluated by $24-\mathrm{h} \mathrm{pH}$ monitoring and later by impedance- $\mathrm{pH}$ monitoring.

Varying methods of questionnaire administration were used over the years in different time segments to evaluate the patient's symptoms, as indicated below:

Group 1: (Study period 1995-1999) The study nurse used the standard questionnaire to ask the patients for the symptoms and marked the answers of the patients regarding presence and severity of the symptoms herself.

Group 2: (Study period 2005-2009) The study nurse handed the questionnaire over to the patients and the patients were left alone to fill in the presence and the severity of the symptoms. The patients could ask for assistance to the nurse, if needed.

Group 3a: (Study period 2015-2017) The study nurse handed the questionnaire over to the patients and the patients were left alone to fill in the presence and the severity of the symptoms in the document.

Group 3b: (Study period 2015-2017) Patients (same patients of Group 3a) were asked to document in a free-text version the 3 most important symptoms that limit or reduce the patient's quality of life. Patients were instructed by the study nurse to document their most relevant symptoms as precisely as possible. Additionally, the study nurse also handed the standard questionnaire over to the patients and the patients were left alone to fill in the presence and the severity of the symptoms. It is important to notice that the free formulated description of the symptoms by the patients themselves was always conducted before the patients filled in the standardized questionnaire. This order was kept with the aim to avoid influences of the standard questionnaire to the patient formulated free text.

The groups were chosen for different time periods, in which changes of the symptom evaluation was established (solicited, selfreported, and free-form self-reported). The standard symptom questionnaire remained the same over the study duration.

\section{Patient Selection and Inclusion/Exclusion Criteria}

The patients were recruited in a tertiary referral center for foregut disorders and its diagnostic functional laboratory and surgery unit. The management of the patients was performed by the same team (same study nurse) over the complete period 1995-2017. The patients were asked to give informed consent to the study evaluation and the diagnostic work-up. The study was approved by our Institutional Review Board.

The data were reviewed in a prospectively maintained databank. Inclusion criteria for this analysis were patients with documented GERD, which required either the presence of esophagitis (esophagitis grading according to Savary-Miller 1-4), pathologic esophageal acid exposure on $\mathrm{pH}$ testing, and/or a hiatal hernia with heartburn and/or regurgitation. The hiatal hernia was documented during endoscopy by measuring the vertical extent of the distance between the cardia (beginning of the gastric folds) and the waist of the crurae, best assessed during inspiration (distance $>1 \mathrm{~cm}$ ). Care was taken to measure this length in the beginning of the endoscopy without major air insufflation of the stomach to avoid hernia reduction.

This analysis was not performed in some time periods (20002004 and 2010-2014), during which the documentation of symptoms was not rigorously followed due to shortage in personnel for 
Table 1. Patients' characteristics for each group

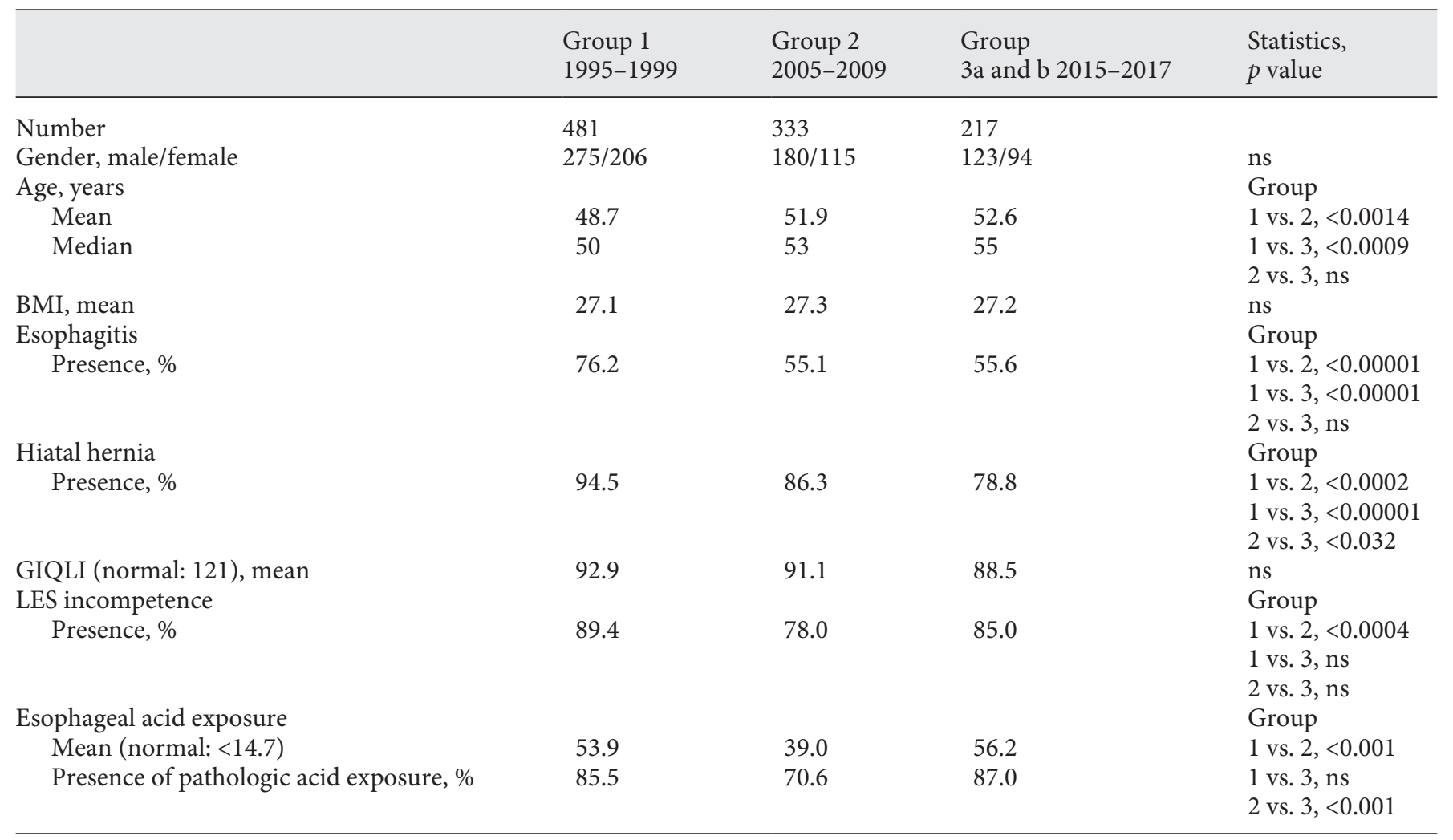

ns, nonsignificant; BMI, body mass index; GIQLI, Gastrointestinal Quality of Life Index; LES, lower esophageal sphincter.

administering the questionnaire. In addition, other exclusion criteria were if patients had other diseases such as cancer, inflammatory bowel disease, esophageal spasm, achalasia, or if they had prior operations for GERD.

\section{The Questionnaire}

For symptom evaluation, a standardized questionnaire was established and used over 25 years. The questionnaire included a graded evaluation of foregut symptoms: heartburn, regurgitation, retrosternal/thoracic pain, respiratory symptoms (cough/hoarseness), dysphagia, epigastric pain (pain/cramps/burning), nausea/ vomiting, fullness (unpleasant fullness, early satiety), and gas-related symptoms (belching/bloating/flatulence). Patients had to document the severity and frequency of each symptom by grading according to the following system: $0=$ no symptoms; $1=$ symptom occurring rarely; 2 = symptom occurring occasionally; 3 = symptom occurring monthly and/or with mild intensity; $4=$ symptom occurring weekly and/or with moderate intensity; 5 = symptoms occurring daily and/or with severe intensity.

\section{Statistical Methods}

Symptom results were analyzed according to their documented overall presence in these patients, independent of their severity, as well as by the most frequently reported significant/ chief complaints. The mean intensity of the presented symptoms was analyzed. Statistical comparison with a $t$ test for unpaired samples was used for the comparison of data from the different samples. A chi-square test was used for comparison of group data.

\section{Results}

From 1995 to 2017, over 2,000 patients with symptoms indicative of GERD were seen by our team. $\mathrm{Pa}$ tients with other gastrointestinal diseases that could influence foregut symptoms were excluded from this study. In total, 1,031 met all inclusion criteria as GERD patients and were enrolled from 3 different time segments. Group 1 (1995-1999) included 481 patients, Group 2 (2005-2009) had 333 patients, and Group 3a/3b (2015-2017) had 217 patients. There were 572 males and 459 females. Table 1 demonstrates the characteristics of patients in the different groups. Presence of esophagitis, evidence of lower esophageal sphincter incompetence, esophageal acid exposure, and the level of quality of life showed severity of GERD among the patients in different groups over the years. 
Table 2. Overview on the percentage of documented symptoms with intensity 5 (chief complaint) differentiated for each group

\begin{tabular}{|c|c|c|c|c|c|}
\hline Symptom & Group 1, \% & $p$ value & Group 2, \% & $p$ value & Group 3a, \% \\
\hline Heartburn & 60 & ns & 61 & ns & 61.6 \\
\hline Regurgitation & 17 & ns & 13.6 & $\begin{array}{l}\text { Group 1: } 0.03 \\
\text { Group 2: } 0.01\end{array}$ & 36.4 \\
\hline Retrosternal pain/cramps & 4.2 & ns & 6.3 & ns & 4.0 \\
\hline Respiratory symptoms: cough, hoarseness & 1.6 & 0.001 & 21.3 & $\begin{array}{l}\text { Group 2: ns } \\
\text { Group 1: } 0.001\end{array}$ & 20.3 \\
\hline Epigastric pain & 13.1 & 0.01 & 24.7 & $\begin{array}{l}\text { Group 2: } 0.02 \\
\text { Group 1: ns }\end{array}$ & 12.1 \\
\hline Nausea, vomiting & 6.6 & ns & 9.7 & ns & 2.0 \\
\hline Fullness & 7.0 & ns & 10.7 & ns & 7.0 \\
\hline "Gas"-related symptoms: belching, bloating, flatulence & 3.3 & 0.01 & 27.2 & $\begin{array}{l}\text { Group 2: ns } \\
\text { Group 1: } 0.01\end{array}$ & 22.0 \\
\hline
\end{tabular}

ns, nonsignificant.

Table 3. Overview on the percentage of overall presence of documented symptoms differentiated for each group

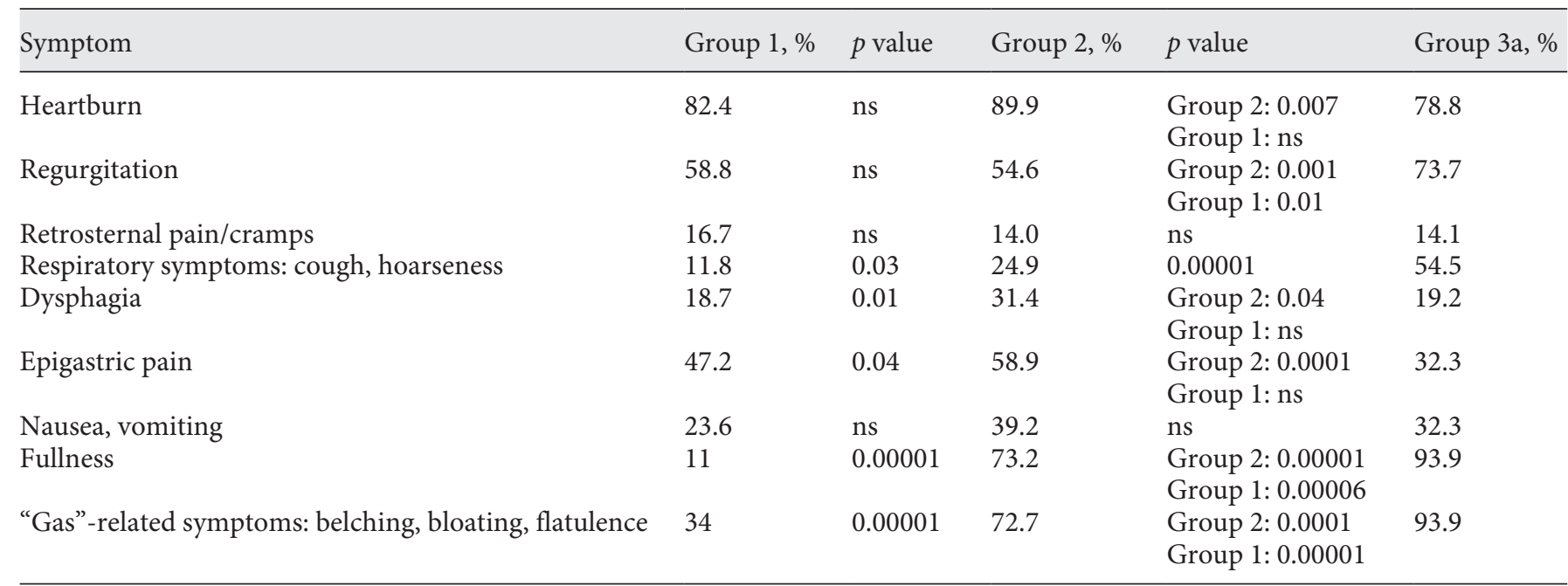

ns, nonsignificant.

Frequency of Chief Complaints and Overall Presence of Symptoms

Heartburn (retrosternal burning rising from the epigastrium to the chest) was the most frequent chief symptom (intensity: 5), independent of exam technique (Table 2: Group 1: 60\%; Group 2: 61\%; Group 3a: 61.6\%; Group 3b: $48.5 \%)$. Table 2 shows the frequency of chief complaints in the different groups. When the questionnaire is filled in by the study nurse (Group 1), the most common symptoms are heartburn and regurgitation $(60 \%, 17 \%)$. Additionally in Group 1, other symptoms such as epigas- tric pain, dysphagia, or gas-related symptoms such as bloating, belching, and flatulence are not often experienced as the primary symptom (frequencies $<15 \%$ ). When comparing between groups, there are significant differences between the reported symptoms (Group 1 vs. Group 2/Group 3a). More often patients self-report respiratory symptoms $(1.6 \%$ vs. $21.3 \% / 20.2 \%$; $p<0.001)$, epigastric pain (13.1\% vs. $24.7 \% / 12.1 \%)$, and gas-related problems $(2.6 \%$ vs. $27.2 \% / 22.0 \%$; $p<0.01)$.

Table 3 provides an overview on the overall presence of symptoms as evaluated in the various time periods. 
Table 4. Overview on percentage of symptoms in a free-text version self-assessed symptoms versus documentation in a self-assessed structured questionnaire

\begin{tabular}{llc}
\hline Symptoms & $\begin{array}{l}\text { Self-assessed } \\
\text { chief complaints } \\
\text { (intensity 5) } \\
\text { in free text, \% }\end{array}$ & $\begin{array}{l}\text { Self-assessed } \\
\text { chief complaints } \\
\text { (intensity 5) in a } \\
\text { structured } \\
\text { questionnaire, \% }\end{array}$ \\
\hline Heartburn & 31 & 62 \\
Regurgitation & 5 & 36 \\
Retrosternal pain & 8 & 4 \\
Respiratory symptoms & 9 & 20 \\
Dysphagia & 1 & 2 \\
Epigastric pain & 9 & 12 \\
Nausea/vomiting & 5 & 2 \\
Fullness & 1 & 7 \\
Gas-related symptoms & 4 & 22 \\
Burning in throat & 7 & - \\
Burning in mouth & 7 & - \\
Globus & 2 & - \\
Dyspnea & 3 & - \\
Headache & 1 & \\
\hline
\end{tabular}

Heartburn and regurgitation are most frequent in Group 1 ( 82.4 and $58.8 \%$, respectively). If patients fill in the questionnaire themselves, there are significant differences between groups in the presence of documentation of respiratory symptoms (Group 1: 11.8\%; Group 2: 24.9\%; Group 3a: 54.5\%; $p<0.01$ ), fullness (1: 11\%; 2: 72.7\%; 3: $93.9 \% ; p<0.001)$, and gas-related symptoms (1: $34 \% ; 2$ : $72.7 \%$; 3: 93.9\%). These differences are even more pronounced in recent years.

\section{Administration of Free-Text Form of Symptom \\ Evaluation}

When patients report their symptoms in their own words prior to completing the standard questionnaire (Group $3 \mathrm{~b}$ ), the documented variety of symptoms increases compared to the structured questionnaire alone (Table 4). In Group 3b, heartburn remains the most frequently reported symptom both as chief complaint (31\%) and in the overall presence (48.5\%). Reported symptoms are much more diversified: burning in the throat (12\%), burning in the mouth (9\%), globus (6\%), headache (1\%), dyspnea (9\%), and fatigue (7\%; Table 4).

Intensity of Symptoms and Their Relation to Objective Functional Data

Data on the intensity of symptoms are summarized in Table 5. The intensity of heartburn is highest in all groups
(Group 1: 3.61; Group 2: 3.88; Group 3a: 3.39). The nurse documented the intensity of the symptoms such as regurgitation, retrosternal pain, epigastric pain, and respiratory symptoms higher (Group 1) than the patients themselves (Groups 2 and 3).

The relationship between symptom intensity and the esophageal functional status show only for heartburn a significant rise in intensity for patients with and without lower esophageal sphincter-incompetence. These differences were for Group 1: 3.1 vs. 3.9; for Group 2: 3.2 vs. 3.9; for Group 3: 1.8 vs. 3.4 (all $p<0.005$ ). The differences in symptom intensity are also significant for some comparisons with regurgitation; however, all other symptoms have no remarkable differences detected for changes in objective functional status.

\section{Discussion}

We show that despite altering modality of questioning and symptom assessment in GERD patients, heartburn is the most frequently reported symptom. The severity and intensity of heartburn were documented to be the highest among all other symptoms through all years of investigation. The reported intensity of heartburn is significantly increased when the functional status of the antireflux barrier deteriorates. On the other hand, the presence/absence and intensity of other symptoms (e.g., regurgitation, respiratory symptoms, bloating) can depend on the concept and details of questioning. Allowing the patients to report free-form selection of symptoms shows a larger variety of documented chief complaints and other gasrelated symptoms that may not be appreciated on standardized questionnaire.

Similar to our study, literature review shows that heartburn is reported to be present in patients with pathologic esophageal acid exposure in $72-99 \%[1,3,14,17,18$, 24-28]. Regurgitation is another important symptom in GERD, with a prevalence of $33-86 \%[1,14,17,29,30]$. According to some studies, epigastric pain is present in patients with foregut symptoms in $70 \%$ and in those with documented pathologic acid reflux in $12-67 \%[1,3,14$, 17]. Our study confirms the importance of heartburn as the classic symptom with the highest intensity and the highest frequency as a chief complaint throughout the study. In Group 3b (free-text format), the symptom of heartburn was further delineated as "burning in the throat" or "burning in the mouth" in up to $14 \%$.

Results of the present study show that the documented presence of symptoms can depend on the method of 
Table 5. Overview on the mean intensity of symptoms differentiated for each group

\begin{tabular}{|c|c|c|c|c|c|}
\hline Symptom & Group 1, \% & $p$ value & Group 2, \% & $p$ value & Group 3a, \% \\
\hline Heartburn & 3.6 & ns & 3.88 & 0.03 & 3.4 \\
\hline Regurgitation & 3.2 & 0.0001 & 1.7 & 0.001 & 2.6 \\
\hline Retrosternal pain/cramps & 3.3 & 0.0001 & 0.5 & ns & 0.5 \\
\hline Respiratory symptoms: cough, hoarseness & 2.4 & 0.0001 & 0.99 & 0.00001 & 1.8 \\
\hline Dysphagia & 2.6 & 0.0001 & 0.9 & ns & 0.5 \\
\hline Epigastric pain & 3.2 & 0.0001 & 2.2 & 0.0001 & 1.1 \\
\hline Fullness & 2.2 & ns & 2.3 & ns & 2.5 \\
\hline "Gas"-related symptoms: belching, bloating, flatulence & 2.5 & ns & 2.3 & ns & 2.4 \\
\hline
\end{tabular}

ns, nonsignificant.

questioning (e.g., whether the symptoms are asked by a study nurse or if the patients are documenting without solicitation). The more the patient is free in her/his answering the questionnaire, symptom variability increases, especially with increased incidence of gas-related and atypical symptoms. The overall presence of heartburn remains independent of questionnaire administration around $80 \%$. Notably, a statistically significant finding of respiratory symptom presence increases from 11 to $50 \%$ and the gas-related symptoms from 30 to $90 \%$ depending on questionnaire modality of application. All other symptoms have a much lower incidence in our GERD patients, and therefore, functional investigations are helpful to confirm the disease if esophagitis is absent.

There has been a controversial discussion about symptoms as a diagnostic tool for the presence of GERD, initiated by the Montreal definition [1, 14, 18-20]. Our study confirms that there is a significant diversity of foregut symptoms present in GERD patients, as well as numerous extra-esophageal complaints such as cough, hoarseness, burning sensation in pharynx, mouth, and tongue in patients [1,14-17]. Extra-esophageal symptoms can be respiratory symptoms such as chronic cough, hoarseness, and shortness of breath [31-38]. There may also be symptoms at the level of the head and neck such as globus or burning in the mouth or throat. Recent studies show limitations of measuring acid reflux in the pharynx with current technology $[37,39,40]$. It remains difficult to correlate these symptoms with reflux episodes, even with objective testing.

We show that our validated questionnaire provides adequate assessment of patient symptoms. Allowing freeform reporting of symptoms in addition to a structured questionnaire may provide a more robust symptom profile in reflux disease. There is evidence in literature that structured questionnaires are very helpful and effective for symptom evaluation, and this is confirmed by our study [41-46]. Several instruments have been published, validated, and successfully used in clinical practice [4146]. Various questionnaires published include the $\mathrm{Pa}$ tient Assessment of Upper Gastrointestinal Symptom Severity Index, the Gastrointestinal Rating Scale, the Chinese GERD Questionnaire, the GERD-Health Related Quality of Life Instrument, the Esophageal Symptoms Questionnaire, and the Reflux Disease Questionnaire [41-43, 47-50]. A systematic review of all the available questionnaires for the assessment of GERD showed that many differ in design, validation, and translation [43]. One should be aware of the strength and shortcomings of each before selecting one for use [43]. All instruments have a self-assessment or self-administered mode of application, usually evaluating severity and/or frequency of GERD symptoms with a median of 15 items (6-30 items) [41-43, 47-50]. The most useful instruments allowed for self-assessment by the patients [43]. However, none of these surveys allow for a free-text version of symptom documentation such as the one tested in this study.

When using the questionnaire over the years we noticed that many patients added remarks in the margin, indicating a possible lack of options or inadequate description. The unprompted free-form clarification of symptoms stimulated the impetus for providing patients more space to document symptoms in this way. None of the available validated questionnaires leaves room for the patient's free text. Variations in patient symptoms such as burning in the mouth, tongue, and throat may be important features to document. In the past, one could only speculate that these symptoms were superficially classified as heartburn or odynophagia. Most of the available structured and validated questionnaires focus on heartburn, epigastric pain, fullness, bloating, regurgitation, and dysphagia. Therefore, it 
may be reasonable to add a free-text section to GERD questionnaires for detection of rare but important symptoms restricting the patient's quality of life.

While expanding structured questionnaires to integrate all possible symptoms would be able to register all symptom variations, the more items to be answered lengthen and complicate the questionnaire process, potentially reducing applicability. Recently developed technologies allow patients to record symptoms in an electronic diary using a mobile electronic device. These technologies may be able to integrate self-administered and free text from evaluations to receive a more realistic and clinically valuable assessment.

Limitations of this study include the retrospective character of the analysis and the long duration of data sampling. Additionally, there were periods of time during the study period where documentation was not able to be rigorously completed due to shortage of nurses (2000$2004,2010-2014$ ), so data from these periods were excluded and sample size reduced as a result. Overall, the size of the patient data sampling performed by one team and one study nurse provides a dependable performance of data sampling and robust data for comparison of the changing techniques of administrating the assessment of GERD symptoms.

GERD remains a disease with a wide variety of symptoms experienced by patients. While heartburn and regur- gitation remain mainstays of symptom reporting, there may be a range of symptoms and intensities of symptoms that go unreported if not elicited in a free-text format. The variety of symptoms experienced also shows the importance of a full correlating objective workup with esophagogastro-duodenoscopy, high-resolution manometry, and impedance-pH testing to assist with accurate diagnosis of patients who may need surgical correction of their disease.

\section{Conclusion}

GERD symptoms are commonly heartburn, regurgitation, fullness, respiratory, and gas/bloat-related. The most important and frequent symptom is heartburn and its intensity parallels objective functional parameters of the esophagus. The overall symptom profile of patients may vary depending on the modality of questioning: practitioner directed, patient questionnaire, or free-form patient reporting of symptoms. Objective studies should be a key component in determining treatment for GERD due to the wide disparity in presenting symptoms.

\section{Disclosure Statement}

The authors have no conflicts of interest to declare.

\section{References}

1 Vakil N, van Zanten SV, Kahrilas PJ. Dent J, Jones R, and the global consensus Group. The Montreal Definition and Classification of gastroesophageal reflux disease: a global Evidence-based Consensus. Am J Gastroenterol. 2006 Aug;101(8):1900-20.

2 El-Serag HB, Sweet S, Winchester CC, et al. Update on the epidemiology of gastro-oesophageal reflux disease: a systematic review. Gut. 2014 Jun;63(6):871-80.

3 Wiklund I, Carlsson J, Vakil N. Gastroesophageal reflux symptoms and well-being in a random sample of the general population of a Swedish community. Am J Gastroenterol. 2006 Jan;101(1):18-28.

$4 \mathrm{Kamolz} \mathrm{T.} \mathrm{Granderath,} \mathrm{Pointner} \mathrm{R.} \mathrm{Laparo-}$ scopic antirefluxsurgery: disease-related quality of life assessment before and after surgery in GERD patients with and without Barrett's esophagus. Surg Endosc. 2003 Jun; 17(6):880-5.

5 Rydberg L, Ruth M, Abrahamsson H, Lundell L. Tailoring antireflux surgery: A randomized clinical trial. World J Surg. 1999 Jun;23(6): $612-8$.
6 Fibbe C, Layer P, Keller J, Strate U, Emmermann A, Zornig C. Esophageal motility in reflux disease before and after fundoplication: a prospective, randomized, clinical, and manometric study. Gastroenterology. 2001 Jul; 121(1):5-14.

7 Dallemagne B, Weerts J, Markiewicz S, Dewandre JM, Wahlen C, Monami B, et al. Clinical results of laparoscopic fundoplication at ten years after surgery. Surg Endosc. 2006 Jan; 20(1):159-65

8 Mehta S, Bennett J, Mahon D, Rhodes M. Prospective trial of laparoscopic nissen fundoplication versus proton pump inhibitor therapy for gastroesophageal reflux disease: sevenyear follow-up. J Gastrointest Surg. 2006 Nov; 10(9):1312-6.

9 Fein M, Bueter M, Thalheimer A, Pachmayr V, Heimbucher J, Freys SM, et al. Ten-year outcome of laparoscopic antireflux surgery. J Gastrointest Surg. 2008 Nov;12(11):1893-9.

10 Strate U, Emmermann A. Fibbe, Layer, P, Zornig C. Laparoscopic fundoplication: nissen versus Toupet two-year outcome of a prospective randomized study of 200 patients re- garding preoperative esophaegal motility. Surg Endosc. 2008 Jan;22(1):21-30.

11 Anvari M, Allen C, Marshall J, Armstrong D, Goeree R, Ungar W, et al. A randomized controlled trial of laparoscopic Nissen fundoplication versus proton pump inhibitors for the treatment of patients with chronic gastroesophageal reflux disease (GERD): 3-year outcomes. Surg Endosc. 2011 Aug;25(8): 2547-54.

12 Frazzoni M, Piccoli M, Conigliaro R, Manta R, Frazzoni L, Melotti G. Refractory gastroesophageal reflux disease as diagnosed by impedance-pH monitoring can be cured by laparoscopic fundoplication. Surg Endosc. 2013 Aug;27(8):2940-6.

13 Fuchs KH, DeMeester TR, Albertucci M. Specificity and sensitivity of objective diagnosis of GERD. Surgery. 1987 Oct;102(4):57580.

14 Costantini M, Crookes PF, Bremner RM, Hoeft SF, Ehsan A, Peters JH, et al. Value of physiologic assessment of foregut symptoms in a surgical practice. Surgery. 1993 Oct;114(4): 780-6. 
15 Tack J, Caenepeel P, Arts J, Lee KJ, Sifrim D, Janssens J. Prevalence of acid reflux in functional dyspepsia and its association with symptom profile. Gut. 2005 Oct;54(10):13706.

16 Savarino E, Pohl D, Zentilin P, Dulbecco P, Sammito G, Sconfienza L, et al. Functional heartburn has more in common with functional dyspepsia than with non-erosive reflux disease. Gut. 2009 Sep;58(9):1185-91.

17 Fuchs KH, Musial F, Ulbricht F, Breithaupt W, Reinisch A, Babic B, et al. Foregut symptoms, somatoform tendencies, and the selection of patients for antireflux surgery. Dis Esophagus. $2017 \mathrm{Jul} ; 30(7): 1-10$.

18 Klauser AG, Schindlbeck NE, Müller-Lissner SA. Symptoms in gastro-oesophageal reflux disease. Lancet. 1990 Jan;335(8683):205-8.

19 Demeester TR, Johnson LF, Joseph GJ, Toscano MS, Hall AW, Skinner DB. Patterns of gastroesophageal reflux in health and disease. Ann Surg. 1976 Oct;184(4):459-70.

20 Eypasch E, Williams JI, Wood-Dauphinee S, Ure BM, Schmülling C, Neugebauer E, et al. Gastrointestinal Quality of Life Index: development, validation and application of a new instrument. Br J Surg. 1995 Feb;82(2):216-22.

21 Fuchs KH, Thiede A, Engemann R, Deltz E, Stremme O, Hamelmann H. Reconstruction of the food passage after total gastrectomy: randomized trial. World J Surg. 1995 SepOct;19(5):698-705.

22 Fein M, Fuchs KH, Thalheimer A, Freys SM, Heimbucher J, Thiede A. Long-term benefits of Roux-en-Y pouch reconstruction after total gastrectomy: a randomized trial. Ann Surg. 2008 May;247(5):759-65.

23 DeMeester TR. Etiology and Natural History of Gastroesophageal Reflux Disease and Predictors of progressive Disease. In: Yeo CJ, DeMeester SR, Mc Fadden DW, editors. Shackelford's Surgery of the Alimentary Tract. 8th ed. Elsevier Philadelphia; 2019. pp. 204-20.

24 Kavitt RT, Higginbotham T, Slaughter JC, Patel D, Yuksel ES, Lominadze Z, et al. Symptom reports are not reliable during ambulatory reflux monitoring. Am J Gastroenterol. 2012 Dec;107(12):1826-32.

25 Bradley LA, Richter JE, Pulliam TJ, Haile JM, Scarinci IC, Schan CA, et al. The relationship between stress and symptoms of gastroesophageal reflux: the influence of psychological factors. Am J Gastroenterol. 1993 Jan;88(1): 11-9.

26 Johnston BT, Lewis SA, Love AH. Stress, personality and social support in gastro-oesophageal reflux disease. J Psychosom Res. 1995 Feb;39(2):221-6.

27 Oustamanolakis P, Tack J. Dyspepsia: organic versus functional. J Clin Gastroenterol. 2012 Mar;46(3):175-90.

28 Lei WY, Chang WC, Wen SH, Wong MW, Hung JS, Yi CH, et al. Impact of concomitant dyspepsia and irritable bowel syndrome on symptom burden in patients with gastroesophageal reflux disease. J Formos Med Assoc. 2019 Apr;118(4):797-806.

29 Kahrilas PJ, Jonsson A, Denison H, Wernersson B, Hughes N, Howden CW. Concomitant symptoms itemized in the Reflux Disease Questionnaire are associated with attenuated heartburn response to acid suppression. Am J Gastroenterol. 2012 Sep;107(9):1354-60.

30 Kahrilas PJ, Jonsson A, Denison H, Wernersson B, Hughes N, Howden CW. Regurgitation is less responsive to acid suppression than heartburn in patients with gastroesophageal reflux disease. Clin Gastroenterol Hepatol. 2012 Jun;10(6):612-9.

31 Kiljander TO, Salomaa ER, Hietanen EK, Terho EO. Chronic cough and gastro-oesophageal reflux: a double-blind placebo-controlled study with omeprazole. Eur Respir J. 2000 Oct;16(4):633-8.

32 Allen CJ, Anvari M. Gastro-oesophageal reflux related cough and its response to laparoscopic fundoplication. Thorax. 1998 Nov; 53(11):963-8.

33 Smith JA, Decalmer S, Kelsall A, McGuinness $\mathrm{K}$, Jones $\mathrm{H}$, Galloway S, et al. Acoustic coughreflux associations in chronic cough: potential triggers and mechanisms. Gastroenterology. 2010 Sep;139(3):754-62.

34 Pacheco-Galván A, Hart SP, Morice AH. Relationship between gastro-oesophageal reflux and airway diseases: the airway reflux paradigm. Arch Bronconeumol. 2011 Apr;47(4): 195-203.

35 Kahrilas PJ, Altman KW, Chang AB, Field SK, Harding SM, Lane AP, et al.; CHEST Expert Cough Panel. Chronic cough due to gastroesophageal reflux in adults: chest guideline and expert panel report. Chest. 2016 Dec; 150(6):1341-60.

36 Ayazi S, Lipham JC, Hagen JA, Tang AL, Zehetner J, Leers JM, et al. A new technique for measurement of pharyngeal $\mathrm{pH}$ : normal values and discriminating $\mathrm{pH}$ threshold. J Gastrointest Surg. 2009 Aug;13(8):1422-9.

37 Fuchs HF, Müller DT, Berlth F, Maus MK, Fuchs C, Dübbers M, et al. Simultaneous laryngopharyngeal $\mathrm{pH}$ monitoring (Restech) and conventional esophageal $\mathrm{pH}$ monitoring-correlation using a large patient cohort of more than 100 patients with suspected gastroesophageal reflux disease. Dis Esophagus. 2018 Oct;31(10): https://doi.org/10.1093/ dote/doy018.

38 Fuchs KH, Babic B, Breithaupt W, Dallemagne B, Fingerhut A, Furnee E, et al.; European Association of Endoscopic Surgery (EAES). EAES recommendations for the management of gastroesophageal reflux disease. Surg Endosc. 2014 Jun;28(6):1753-73.

39 Wilhelm D, Jell A, Feussner H, Schmid RM, Bajbouj M, Becker V. Pharyngeal pH moni- toring in gastrectomy patients - what do we really measure? United European Gastroenterol J. 2016 Aug;4(4):541-5.

40 Nennstiel S, Andrea M, Abdelhafez M, Haller B, Schmid RM, Bajbouj M, et al. pH/multichannel impedance monitoring in patients with laryngo-pharyngeal reflux symptoms - Prediction of therapy response in long-term followup. Arab J Gastroenterol. 2016 Sep;17(3):113-

41 Dent J, Vakil N, Jones R, Bytzer P, Schöning $\mathrm{U}$, Halling K, et al. Accuracy of the diagnosis of GORD by questionnaire, physicians and a trial of proton pump inhibitor treatment: the Diamond Study. Gut. 2010 Jun;59(6):714-21.

42 Jones R, Junghard O, Dent J, Vakil N, Halling K, Wernersson B, et al. Development of the GerdQ, a tool for the diagnosis and management of gastro-oesophageal reflux disease in primary care. Aliment Pharmacol Ther. 2009 Nov;30(10):1030-8.

43 Bolier EA, Kessing BF, Smout AJ, Bredenoord AJ. Systematic review: questionnaires for assessment of gastroesophageal reflux disease. Dis Esophagus. 2015 Feb-Mar;28(2):105-20.

44 Koloski NA, Jones M, Hammer J, von Wulffen M, Shah A, Hoelz H, et al. The validity of a new structured assessment of Gastrointestinal Symptoms scale (SAGIS) for eevaluating symptoms in the clinical setting. Dig Dis Sci. 2017 Aug;62(8):1913-22.

45 Hui D, Bruera E. The Edmonton Symptom Assessment System 25 Years Later: Past, Present, and Future Developments. J Pain Symptom Manage. 2017 Mar;53(3):630-43.

46 Monroy M, Ruiz MA, Rejas J, Soto J. Mapping of the Gastrointestinal Short Form Questionnaire (GSF-Q) into EQ-5D-3L and SF-6D in patients with gastroesophageal reflux disease. Health Qual Life Outcomes. 2018 Sep 10;16(1): 177.

47 Wong WM, Lam KF, Lai KC, Hui WM, Hu $\mathrm{WH}$, Lam CL, et al. A validated symptoms questionnaire (Chinese GERDQ) for the diagnosis of gastro-oesophageal reflux disease in the Chinese population. Aliment Pharmacol Ther. 2003 Jun;17(11):1407-13

48 Rentz AM, Kahrilas P, Stanghellini V, Tack J, Talley NJ, de la Loge C, et al. Development and psychometric evaluation of the patient assessment of upper gastrointestinal symptom severity index (PAGI-SYM) in patients with upper gastrointestinal disorders. Qual Life Res. 2004 Dec;13(10):1737-49.

49 Velanovich V. The development of the GERD-HRQL symptom severity instrument. Dis Esophagus. 2007;20(2):130-4.

50 Kwiatek MA, Kiebles JL, Taft TH, Pandolfino JE, Bové MJ, Kahrilas PJ, et al. Esophageal symptoms questionnaire for the assessment of dysphagia, globus, and reflux symptoms: initial development and validation. Dis Esophagus. 2011 Nov;24(8):550-9. 